\title{
Income inequality in New Zealand: Why conventional estimates are misleading
}

\author{
John Creedy and Norman Gemmell
}

\section{Abstract}

Considerable attention is now paid to establishing the extent of inequality in New Zealand and whether it has risen in recent years. This paper offers some insights into the inequality measures and interpretations that commonly feature in those debates. These typically relate annual Gini coefficients for various income definitions, or comparisons of income growth rates across income deciles. But cross-sectional data fail to take into account the longitudinal dimension of inequality, and this can lead to misinterpretations of inequality data. The paper shows that examining longitudinal income data for the same individuals over time strongly contradicts some apparent messages of cross-sectional evidence. For example, some recent cross-sectional inequality measures suggest that the incomes of initially low-income households grew at slower rates than those with initially higher incomes. This has been interpreted as the poorest earners being 'left behind'. But recent longitudinal data, at least for individuals, reveals evidence of much faster-than-average growth among initially lower, compared to higher, income earners. Thus, 'regression to the mean' is a dominant feature of the longitudinal data.

\footnotetext{
1 John.creedy@vuw.ac.nz, Victoria University of Wellington; Victoria University of Wellington. The authors are very grateful to a referee for helpful comments on an earlier draft of this paper.
} 


\section{Introduction}

A great deal of attention is currently being paid to establishing the extent of inequality in New Zealand and whether it has risen in recent years. With the work of the Labour Government's 2018 Tax Working Group well underway, and a proposed Welfare Working Group also to be established, the ability of tax and welfare policy to affect the inequality properties of the income distribution has also become a central political issue.

When summarising inequality, commentators generally recognise the need to specify the precise income measure, whether it is pre-tax or disposable income, or consumption expenditure. They also usually make the important distinction between individual and household or family incomes, where use of the latter recognises income sharing within households and differing needs of adults and children, along with possible economies of scale in consumption expenditure. Hence, results are often obtained where the 'household income per adult equivalent person' is treated as if it is obtained equally by each household member. ${ }^{2}$

However, considerably less attention is usually paid to the time period, or accounting period, over which income is measured, yet this has important implications not only for orders of magnitude but for attitudes to measured inequality. This is easily illustrated using the simplified case of just two individuals (A and B) and two time periods ( 1 and 2), where 100 income units are available in total in each period (and discounting is ignored). Suppose A receives 80 units in period 1 and 20 units in period 2, while B receives 20 units in period 1 and 80 units in period 2. The only difference between the individuals is that they have different time patterns of income.

When measured over a single period there is substantial inequality (in each year the richer person obtains four times the income of the poorer person), but over the two periods they have equal total incomes of 100 units each. The attitude to inequality in this case is likely to differ substantially from a situation in which there is rigidity in the distribution and person $A$ receives 80 units in each period. Of course, attitudes are also likely to depend significantly on the reasons for the relative income changes, and while some equalising mobility is likely to be regarded as 'good', reflecting opportunities for improvement, there could be 'excessive' mobility if this

2 A set of 'adult equivalent scales' is used by which each individual is assigned an 'adult equivalent size' (with a value of 1 for adult males). This assumption is not 'innocent', in that equal sharing is a strong assumption, made pragmatically in the face of a lack of information. Furthermore, the use of the individual as the 'income unit' in producing inequality measures can actually lead to a preference for inequality: that is, a transfer from a poorer to a richer household may be preferred if the richer household is larger and has substantial economies of scale in consumption. For an introduction to the issues involved in the choice of income unit, see Creedy (2017). 
reflects considerable uncertainty. The choice of time period clearly depends, like that of the income and inequality measures used, on value judgements: there is no unambiguously 'correct' or 'objective' measure. ${ }^{3}$

The relationship between short- and long-period measures of inequality, while complex, clearly depends on the precise nature of relative income mobility. While the most common summary measures are reported for annual incomes, it is argued here that comparisons should be supplemented by information about such mobility. This requires the use of longitudinal data, whereby individuals or households can be tracked over a number of periods. Although such data are relatively scarce for New Zealand, failure to take into account the longitudinal and mobility dimensions of inequality can lead to misinterpretations of reported inequality measures.

For example, most of the inequality measures quoted in recent New Zealand debates relate to cross-sectional inequality, such as Gini coefficients for various income definitions across a number of years. When considering income changes over time, comparisons of income growth rates of deciles of the annual income distributions are made, using only cross-sectional data. Hence, this does not identify how far the same people remain towards the bottom or top of the income distribution, or the extent to which movement within the distribution occurs over time.

This paper examines some scarce longitudinal income data for individual New Zealand taxpayers and shows that, whereas inequality measures based on population cross-sections tend to suggest that the income of (initially) lower-income groups grew at similar or slower rates than those with initially higher incomes, this is strongly contradicted by longitudinal data. Indeed, there is conclusive evidence of faster-than-average growth for those with initially lower incomes. The phenomenon of 'regression to the mean' seems to be a dominant feature of the longitudinal data. ${ }^{4}$

First, section 2 briefly summarises the evidence usually provided about crosssectional (annual) income inequality in New Zealand, and about differential income growth rates. Section 3 demonstrates how longitudinal income data, to measure relative income changes of individuals (rather than changes in deciles of annual income), provide valuable additional information that has typically been ignored in popular debates. This section makes use of Inland Revenue Department data which track a constant sample of individuals over a number of years. The data necessarily refer to individuals, which is the relevant unit used for income tax assessments.

3 The choice also depends on the context. For example, weekly incomes display considerable variability compared with longer-period incomes, yet a case may be made for a redistributive transfer system based on weekly incomes. Broader judgements about income inequality and the desired progressivity of an income tax structure may continue to be based on the use of a longer accounting period. For example, students may be poor in annual terms but subsequently rich in terms of lifetime incomes.

4 This phenomenon has also been observed to be strong in earlier studies for New Zealand: see, for example, Creedy (1996), Creedy et al. (2018). 
Hence, they cannot reflect the way these are combined into families or households, or the extent to which they may be shared. Brief conclusions are in section 4 . All dollar values discussed are in New Zealand dollars.

\section{Cross-sectional inequality evidence}

Contributors to New Zealand policy debates on income inequality invoke a variety of inequality measures for alternative definitions of income. Two readily available indicators are the taxable income distributions from Inland Revenue and the numerous distributional measures reported in Ministry of Social Development (MSD, 2017, and previous annual editions). Two examples are given below to illustrate the type of comparison given. Table 1 shows the percentage of taxpayers, taxable income and assessed tax paid by the top and bottom 10 per cent (approximately) of the tax-paying population, and similar values for the top and bottom 50 per cent.

Table 1. Percentage shares: 2016 distribution of individual taxpayers in New Zealand (excluding zero taxable incomes)

\begin{tabular}{|l|l|l|l|l|}
\hline Year: 2016 & Taxpayers (\%) & Taxable income (\%) & Assessed tax (\%) & Income range (\$) \\
\hline Bottom & 9.7 & 0.7 & 0.4 & 1 to 7,000 \\
\hline Top & 10.0 & 33.5 & 45.4 & 87,001 to $150,000+$ \\
\hline Bottom & 49.5 & 17.2 & 10.6 & 1 to 31,000 \\
\hline Top & 50.5 & 82.8 & 89.4 & 31,001 to $150,000+$ \\
\hline
\end{tabular}

Source: Authors' calculations using Inland Revenue data: www.ird.govt.nz/aboutir/external-stats/ revenue-refunds/income-distrib-individual-customers/income-distrib-individ-customers.html.

Table 1 reveals that the lowest 9.7 per cent of taxpayers (earning from $\$ 1$ to $\$ 7,000$ per year) received less than 1 per cent of all taxable income, while the top 10 per cent (earning over $\$ 87,000$ in 2016) received around 34 per cent of total taxable income. However, those low-income taxpayers are on very low incomes. By comparison, the annual gross-of-tax New Zealand Superannuation (pension) in 2016 was around $\$ 23,000$ for a single person. Hence the lowest 10 per cent of taxpayers are likely to be part-time earners, students or children, who are all subject to large transitory income changes over time; see Creedy, Enright, Gemmell and McNabb (2010) for a detailed decomposition of the lowest income taxpayers by type. ${ }^{5}$ This serves to

\footnotetext{
5 New Zealand, by virtue of having no tax-free zone, has a relatively large number of income taxpayers compared with Australia. It is hard to make comparisons because Australian income taxpayer data are generally reported for numbers of individual income tax returns, whilst only around 2.2 million of New Zealand's 3.7 million individual income taxpayers are required to submit a tax return, or receive a 'personal tax summary (PTS)'. Where a PTS is issued by Inland Revenue, this obviates the need to submit a tax return unless the taxpayer considers the PTS is incorrect. The tax liabilities of remaining income taxpayers in New Zealand are fully covered by the pay-as-you-earn system.
} 
emphasise the limited value of focusing on the lowest income decile (or indeed the lowest two deciles, with incomes below $\$ 15,000$ in 2016) since these are unlikely to provide a representative picture of individuals in income poverty.

Based on the same data source, Figure 1 shows how the share of total taxpayers with incomes of $\$ 0, \$ 1$ to $\$ 5,000$, and $\$ 1$ to $\$ 7,000$ changed over the 2001-16 period for which comparable data are available. Figure 1 shows how the share of those on very low incomes has changed over the 2001-16 period. It can be seen that $\$ 0$ earners represent about 3 to 4 per cent of all taxpayers, with a slight decline in recent years. The figure also shows the share of taxpayers earning less than $\$ 5,000$ and $\$ 7,000$ per year. This reveals a steady decline in both groups, which might be expected since these nominal income thresholds represent declining real incomes over the period. However, CPI data for the period shows that $\$ 5,000$ in 2001 is approximately equal in real terms to $\$ 7,000$ in 2016 . Hence, in real terms, the 2016 value for ' $\$ 1$ to $\$ 7,000$ ' can be compared with the 2001 value for ' $\$ 1$ to $\$ 5,000$ '. This indicates that the share of taxpayers with those low real incomes fell from around 11.2 per cent in 2001 to 9.4 per cent in 2016 . That is, the proportion of the lowest (real) income taxpayers has fallen over the 15 years.

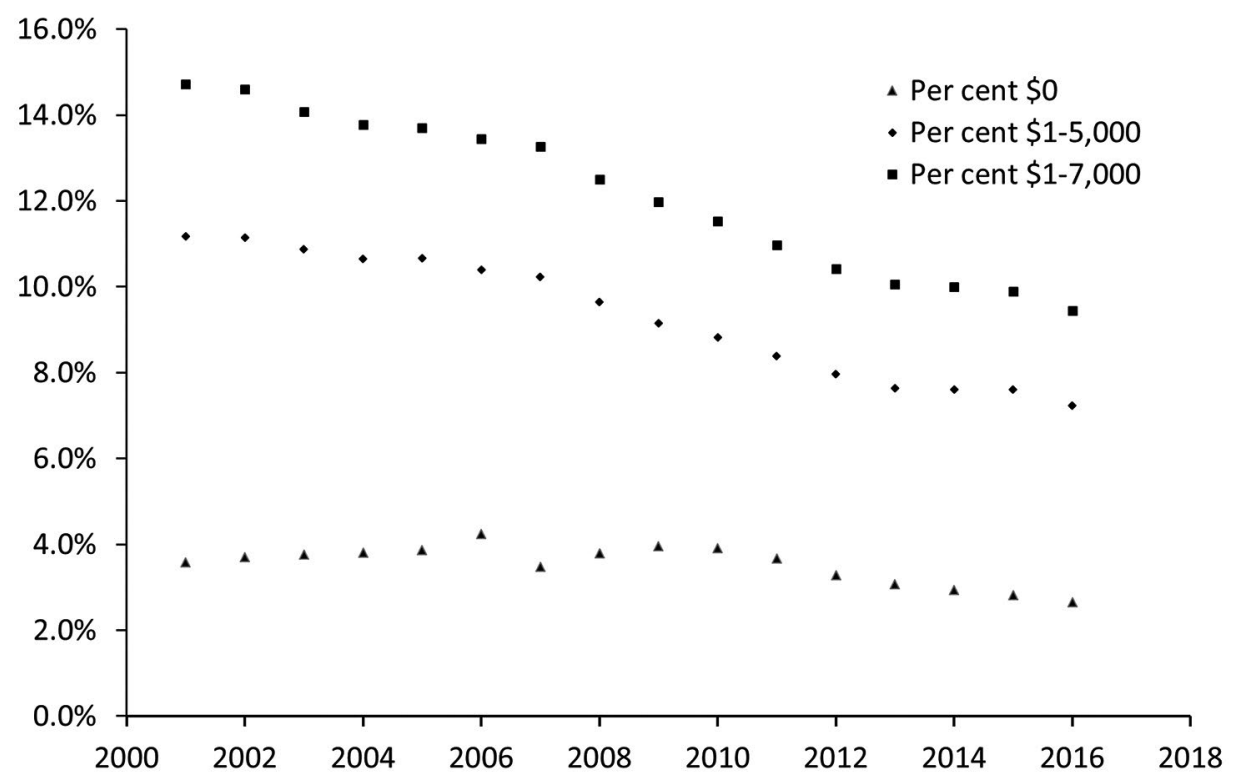

Figure 1. Percentage of all income taxpayers on zero or low incomes: New Zealand 2001 to 2016

Source: Authors' calculations using Inland Revenue data: www.ird.govt.nz/aboutir/external-stats/ revenue-refunds/income-distrib-individual-customers/income-distrib-individ-customers.html. 
These data are of course highly selective, focusing on small segments of the taxpaying population, and are based on a series of annual cross-sections of the income distribution. More comprehensive coverage of household incomes, rather than individual taxpayers, but still based on annual cross-sectional data, is provided by MSD in their regular publication on household incomes in New Zealand; see, for example, MSD (2016, 2017). Since households differ by size and composition, as mentioned in section 1, MSD use total household income per adult equivalent person as their income measure, and use the individual as unit of analysis. Two of their examples are shown in Figures 2 and 3.

Figure 2 shows deciles of the distribution of annual household incomes after housing costs, for 1982 to 2016 (using data from MSD (2017, p. 76, Table D6). ${ }^{6}$ Their commentary states:

from a longer-term perspective: in HES 2016, household incomes at the top of the bottom decile were no better than they were in the 1980s. This is the only decile for which this is the case, though for P20 the gain is small (MSD, 2017, p. 75).

More generally, these data have been interpreted incorrectly as evidence of the lower-income deciles 'falling behind' the top deciles in real income growth, or even that real incomes are falling absolutely for lower-income households. ${ }^{7}$

These messages appear to be reinforced by evidence on the income growth rates by decile of the income distribution, such as those shown in Figure 3, compiled from the same data used for Figure 2, for a 'post global financial crisis period' (2009 to 2016). This shows larger income growth rates for those in initially higher-income deciles compared to lower deciles. ${ }^{8}$ That is, richer households seem to be moving away from poorer households in terms of their real income levels, over the period.

\footnotetext{
6 Overall patterns look similar when based on incomes before housing costs (BHC), though there is more evidence of higher real incomes for the lowest deciles at the end of the period compared to the 1980s; see MSD (2017, p. 75).

7 For example, examining data for income growth over a longer period, 1982 to 2015, MSD (2016, p. 65) conclude that 'all income groups gained in real terms, with the highest income group gaining much more than the rest, and the lowest income group gaining the least. The different growth rates show that income inequality is higher in HES 2015 than in 1982'. However, they later point out that this cannot capture income changes for 'the same individuals over time' (MSD, 2016, p. 65). Similarly, Rashbrooke (2013) misleadingly claims, 'in the last thirty years, incomes for our richest New Zealanders has more than doubled, while those of the poorest have barely increased - and in fact are lower now than they were in the 1980s if you take their increased housing costs into account'; see www.inequality.org. $\mathrm{nz} /$ understand/narrative/. These statements give the misleading impression that they relate to income growth of those with initially lower and higher incomes yet they are not based on longitudinal data.

8 The growth rates here refer to income growth rates for the household at each decile: 1 (at the 10th percentile), 2 (at the 20th percentile), and so on, of the income distribution, not average growth rates for households between relevant deciles; for example, between the 10 th and 20 th percentiles.
} 


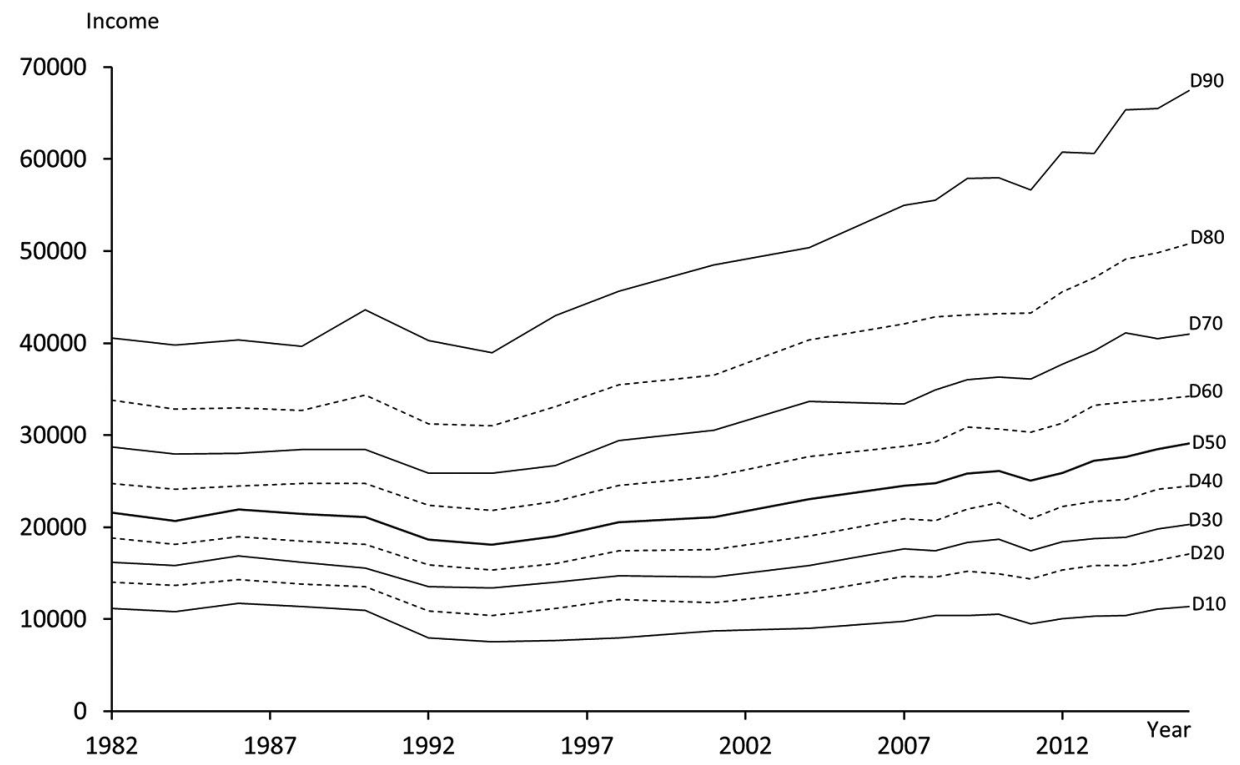

Figure 2. Real equivalised household incomes after housing costs at decile boundaries, 1982-2016

Source: Authors' calculations using MSD (2017, p. 76, Table D6).

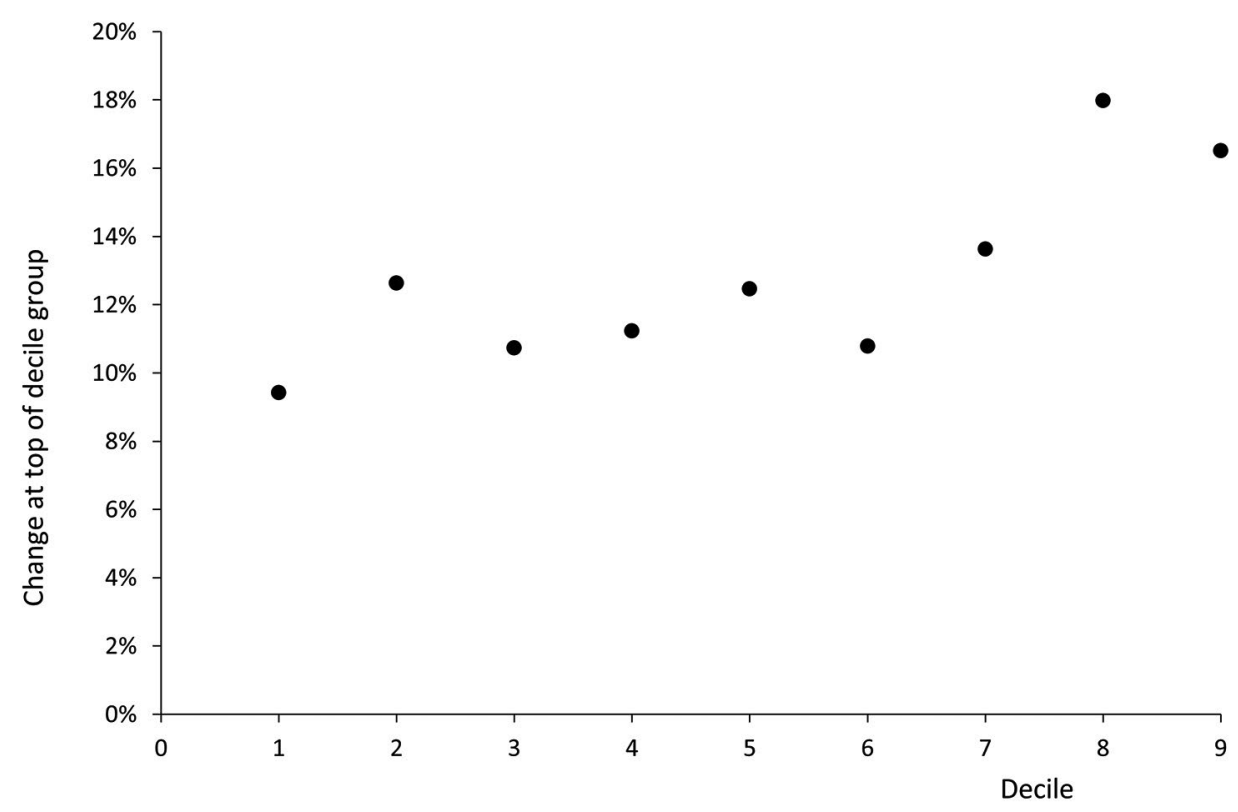

Figure 3. Real equivalised household incomes: Changes at each decile Source: Authors' calculations using MSD (2017, p. 76, Table D6). 
However, such an interpretation is based on a misunderstanding of the difference between income growth rates for different individuals with the same low initial incomes' and 'income growth for the same individuals with initially low incomes'. The former is observed from a series of cross-sectional 'snapshots' such as those mentioned previously, whereas the latter requires longitudinal data for the same individuals over time. Longitudinal evidence for New Zealand is examined in the next section. ${ }^{9}$

\section{Inequality evidence from longitudinal data}

To examine longitudinal income data comparable to the cross-sectional evidence for households presented in section 2, it would be necessary to track the same households over time. Unfortunately, data to allow this for New Zealand are currently limited to the Survey of Family Income and Employment (SoFIE) data, which are only available for the 2002 to 2010 period, for a relatively small sample. ${ }^{10}$ With the increasing scope and availability to researchers of matched household-level data in the Integrated Data Infrastructure at Statistics New Zealand, such longitudinal household income analyses may soon be possible.

However, it should be recognised that the use of households is considerably complicated by the fact that their size and composition changes over time, as a result of births, deaths, family division and formation, and so on. The use of individual data in this section avoids those complications, but at the cost that changes in individuals' income over time may not necessarily indicate equivalent changes in household incomes. Nevertheless, observed differences between cross-sectional and longitudinal patterns of income change for individuals might be expected to provide some guidance on the potential for similar differences at the household level.

$9 \operatorname{MSD}(2016$, p. 65) points out this distinction by stating that,

In interpreting the time series analysis that is based on the HES data (as above), it is important to understand that the HES provides repeat cross-sectional data with different people interviewed each survey. The HES does not follow the same individuals across time. Some individuals do stay in roughly the same income band for many years, some move up and some move down. The degree of income mobility in New Zealand is discussed in Section K using longitudinal data from Statistics New Zealand's Survey of Family, Income and Employment (SoFIE).

Unfortunately, SoFIE data cover only a limited number of years: 2002-09, and many commentators continue to ignore the above warning.

10 See Carter and Gunasekara (2012) for some SoFIE-based mobility evidence. There are around 18,000 individuals in each of the seven waves of their SoFIE samples. The number of individuals in the Inland Revenue data used in section 3 exceed 30,000. 
With access to Inland Revenue's confidentialised longitudinal individual taxpayer data, Creedy and Gemmell $(2017,2018)$ examined the growth rates of taxpayer incomes across the individual (as opposed to household) income distribution for three five-year periods: 1998 to 2002, 2002 to 2006 and 2006 to 2010. This section reports on some of those longitudinal results and assesses them against directly comparable cross-sectional evidence.

The data used in this section are for a 2 per cent random sample of individual New Zealand Inland Revenue personal income taxpayers. Using data for 2002, 2006 and 2010, results for two separate panels are reported for 2002 to 2006 and 2006 to 2010, each (5-year) panel containing incomes for both years for the same taxpayers. This yielded useable samples of 31,355 and 32,970 individuals respectively. To avoid the exercise being contaminated by taxpayers with very low incomes (such as small part-time earnings of children, or small capital incomes of non-earners), individuals with annual incomes less than $\$ 1,000$ were omitted from the sample.

Appendix Table A1 provides details of income levels in each sample - averages within income ventiles (20 equal-sized divisions) and at equivalent percentiles $(0.05,0.10$, 0.15 etc.). As might be expected using individual data, even eliminating incomes below $\$ 1,000$, there are still substantial numbers of taxpayers on low incomes. For example, the sample 25th percentile income in 2006 was $\$ 16,924$, around the level of the New Zealand state pension (NZ Superannuation) for a married person. ${ }^{11}$ Individual taxpayers in the lowest income ventiles in this dataset might therefore be expected in general to be members of households that include other income sources.

To identify longitudinal aspects, in each case individuals were ranked by their initial year incomes (2002 or 2006), with all of the diagrams below showing percentiles of the income distribution in the relevant initial year (2002 or 2006) on the horizontal axis. For cross-sectional comparisons, individuals were ranked in each of the two years, regardless of their rank in the previous or subsequent year. That is, they represent income distributions of different rankings of individuals that ignores their prior or subsequent status.

Figures 4 and 5, covering the periods 2002 to 2006 and 2006 to 2010 respectively, capture both longitudinal and cross-sectional aspects of inequality in the form of several Lorenz curves. In each panel, two cross-sectional Lorenz curves are shown where individuals are ranked by their incomes in the initial and final year: 2002 and 2006 in Figure 4; and 2006 and 2010 in Figure 5.

11 Most taxpayers receiving only NZ Superannuation are typically in the 2nd and 3rd deciles; see www.ird.govt. $\mathrm{nz} /$ aboutir/external-stats/revenue-refunds/income-distrib-individual-customers/income-distrib-individ-customers. html. The longitudinal sample percentile incomes in Appendix Table A1 are somewhat different from those reported in Table 1 previously, which refers to all New Zealand income taxpayers. 


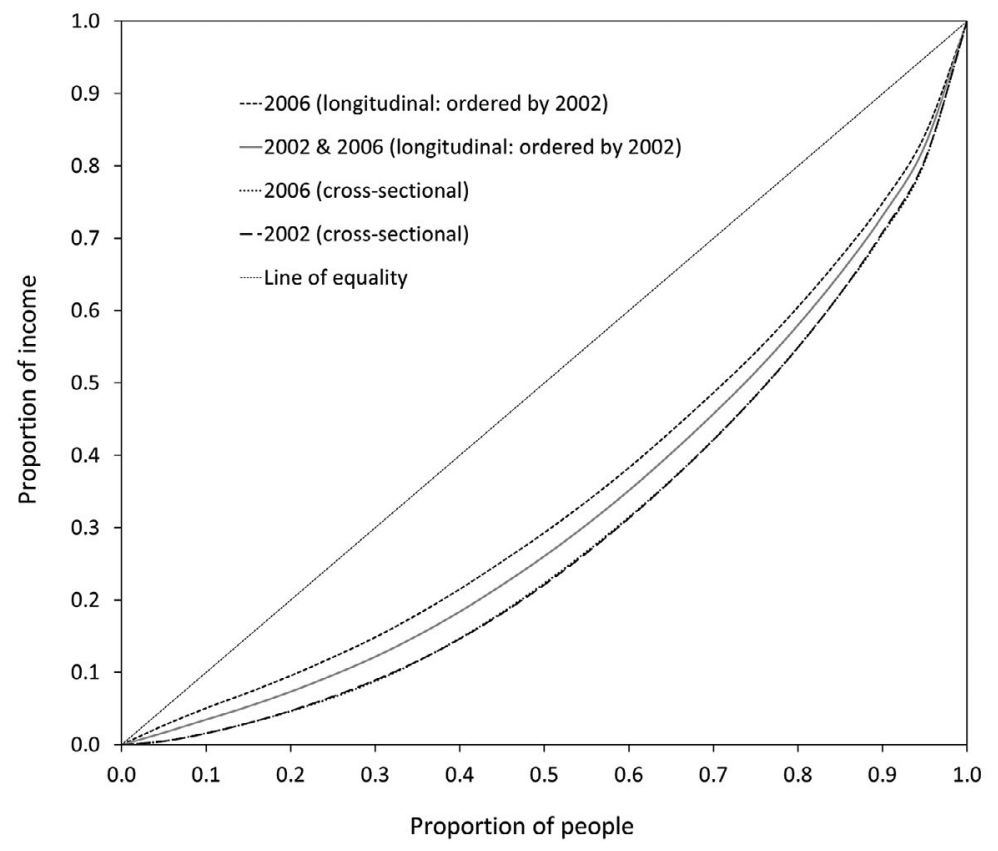

Figure 4. Lorenz curves: New Zealand taxpayers 2002 to 2006

Source: Authors' calculations using unpublished Inland Revenue confidentialised individual taxpayer data (a 2 per cent random sample made available to the authors).

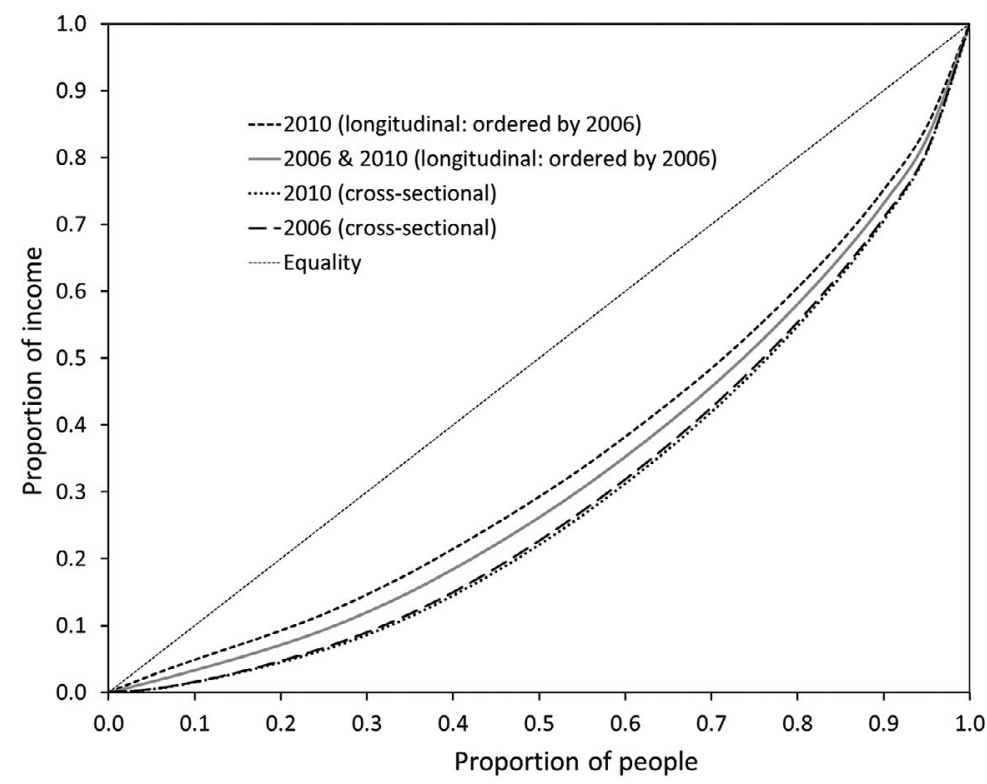

Figure 5. Lorenz curves: New Zealand taxpayers 2006 to 2010

Source: Authors' calculations using unpublished Inland Revenue confidentialised individual taxpayer data (a 2 per cent random sample made available to the authors). 
In both figures, the two Lorenz curves can be seen to be almost indistinguishable from each other, indicating little difference in a Gini-based cross-sectional measure of inequality for each year. For 2010, the Lorenz curve mostly lies slightly outside the 2006 equivalent, though some crossing of the two curves can also be seen. Two important messages arise from those charts.

First, it is known that increasing the length of the accounting period tends to reduce inequality measures such as the Gini coefficient, for example as incomes are measured over 1, 2, 5, 10 years and so on. ${ }^{12}$ This aspect is evident in Figure 4 and Figure 5, where incomes in both years for each individual are added (and the average ranked by initial year incomes). While this does not include incomes for all years over the two five-year periods, it does demonstrate the effect of extending the accounting period.

It can be seen that this Lorenz curve for two years of income data lies wholly inside the two equivalent curves for 2002 and 2006 (Figure 4) or 2006 or 2010 (Figure 5). That is, longer-term incomes display noticeably less inequality than either of the annual cross-sections. These curves confirm that substantial reductions in inequality, as the income period is lengthened, are consistent with the relatively unchanged cross-sectional patterns that are also observed in Figures 4 and 5.

Secondly, in Figure 5, when longitudinal dimensions are introduced explicitly by ordering income in both 2006 and 2010 for each individual by their 2006 incomes, a further distinct reduction in inequality is apparent. That is, the '2010 longitudinal (ranked by 2006)' curve lies everywhere closer to the line of equality than any of the other curves in the chart. Similar patterns can be observed in Figure 4 for 2002 to 2006. The Gini coefficient is the area between the Lorenz curve and the line of equality, expressed as a fraction of the total area below the line of equality. Hence, it follows that for both these periods the 'longitudinal-based Gini' must be smaller than the cross-sectional based Gini.

An alternative, and in some ways more insightful, means of comparing the different inequality outcomes captured by cross-sectional and longitudinal dimensions of the data, is to examine growth rates over the two periods, 2002 to 2006 and 2006 to 2010 , by different groups within the (initial) income distribution. These are shown by ventiles of the income distribution in Figures 6 and 7, for 2002 to 2006 and 2006 to 2010 respectively, which allow for a more fine-grained comparison than income deciles. The cross-sectional growth rates by ventile are obtained by ranking individual incomes from lowest to highest separately for each year. Growth rates are then estimated for the incomes of the lowest to the highest individual, who will generally not be the same person in both years.

12 See, for example, Laws (2014) and Creedy et al. (2018) for New Zealand evidence. 
These growth rates are then averaged within ventiles; with over 30,000 individuals in total there are in excess of 1,500 in each ventile. These are shown by the hatched bars in Figures 6 and 7, with values on the horizontal axis representing the ventile, $0.5,0.10, \ldots, 0.95,1.0$. Longitudinal growth rates, on the other hand, relate to the income growth of the same individual with ventiles based on the initial income ranks (in 2002 or 2006).

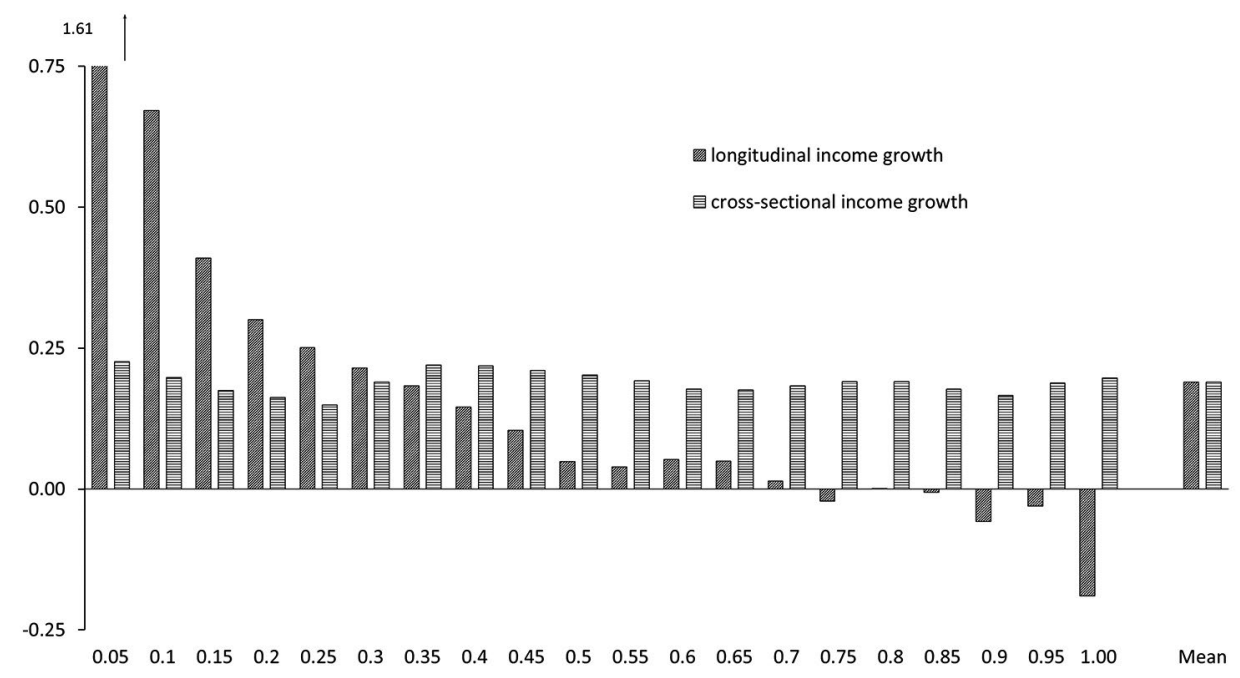

Figure 6. Income growth rates: New Zealand taxpayers 2002 to 2006

Source: Authors' calculations using unpublished Inland Revenue confidentialised individual taxpayer data (a 2 per cent random sample made available to the authors).

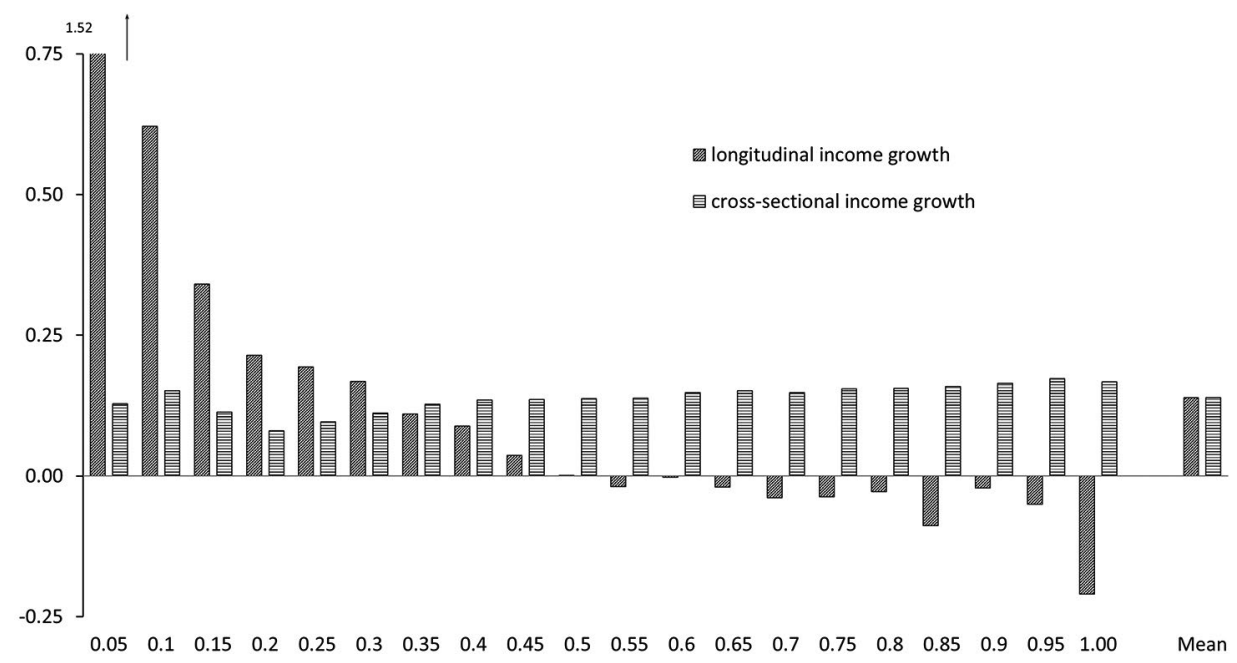

Figure 7. Income growth rates: New Zealand taxpayers 2006 to 2010

Source: Authors' calculations using unpublished Inland Revenue confidentialised individual taxpayer data (a 2 per cent random sample made available to the authors). 
It can be seen in Figure 6, for 2002 to 2006, that growth rates based on crosssectional data are similar across ventiles, with most generally close to the mean for the whole sample, and there is no obvious pattern towards systematically higher or lower growth rates across the ventiles. By contrast, the (solid) longitudinal-based growth rates demonstrate that income growth over the five years was systematically higher for low-income, compared to high-income, ventiles, with clear evidence of substantial regression towards the mean across the ventiles.

For example, on average individuals who were initially in the lowest 5 per cent of incomes in 2002 experienced much faster income growth over the period 2002 to 2006 than individuals in the highest ventiles. Indeed, for those in above-median ventiles, income growth was negative on average, especially for the top 5 per cent of taxpayers. A similar pattern is observed in Figure 7 for 2006 to 2010, but here the cross-sectional income growth rates demonstrate some tendency for higher ventiles to experience faster growth than lower ventiles (at least for those from around 0.2 upwards). Longitudinal-based ventiles, however, continue to reveal that when the same individuals are observed, the initially lowest income taxpayers experienced the fastest subsequent income growth.

In both Figures 6 and 7 a strong pattern is the negative association of income growth rates with ventile income levels across the whole distribution; that is, it is not simply the lowest and highest ventiles that display this tendency. Hence, although the income data for individuals used here include some very low incomes (that would be expected to be much less prevalent with household-level data), it seems that differences in the cross-sectional/longitudinal growth rate patterns are not simply due to income volatility experienced by those with low incomes in one year.

Figures 6 and 7 therefore highlight that if inequality of income growth experience is assessed by reference to cross-sectional growth rates across ventiles or deciles, it can lead to the impression that the poorest are being 'left behind', as those on initially higher incomes experience faster growth. However, this obscures the evidence that if income growth rates are based on the initial income distribution, this conclusion is not supported; indeed, it is radically reversed. Some initially higher-income individuals move down the income distribution over time, and vice versa, such that when comparing the incomes of the 'old lowest' to the 'new lowest', observed income growth rates are similar. ${ }^{13}$

13 Using data from the Household, Income and Labour Dynamics in Australia (HILDA) survey, Azpitarte (2014) reports a similar contrast between income growth rates obtained using longitudinal and cross-sectional data. 
Given these 'regression towards the mean' patterns, it might be expected that income inequality measured over several years would be less than when measured over a single year. In fact, this motivated Shorrocks (1978) to propose a measure of income mobility or 'rigidity' based on comparing an index of longer-term income inequality to single-year income inequality. ${ }^{14}$

This phenomenon has been observed for a similar longitudinal sample of New Zealand income taxpayers by Creedy, Gemmell and Laws (2018), covering a 19-year period from 1994. These are illustrated in Figure 8, which shows Gini inequality indices for taxable incomes over those years. In each case the profiles show the Gini index calculated using incomes aggregated over 1, 2, 3, .. 19 years, beginning in 1994 or 2001. ${ }^{15}$ Profiles are shown for all taxpayers in the sample and for 'workingage' taxpayers only (those aged 24-64 throughout the period) - since retirement can be associated with a substantial drop in income around age 65 .

All four profiles show that the inclusion of incomes for an additional year consistently results in a reduction in the Gini coefficient, with the exception of year 7 for the ' 1994 start' profile; that is, when the 2001 income data are included. This reflects the impact of the increase in the top rate of income tax from 33 per cent to 39 per cent in 2001 which was associated with (especially) top incomes being diverted from the personal income tax schedule and possibly increased income sharing among partnered individuals. The figure therefore confirms, as expected, that allowing for taxable incomes received over a longer period generates a lower inequality outcome than is observed for each annual income distribution on its own. For example, the ratio of the Gini for 19 years of income to the Gini for the first year (1994) is 0.811 (all ages) and 0.855 (working age). ${ }^{16}$

\footnotetext{
14 The Shorrocks (1978) measure of 'rigidity', R, involves constructing the ratio of an index of the inequality of T-year incomes to an equivalent weighted average index of income inequality in the $\mathrm{T}$ single years.

15 Data for a longitudinal panel from 2001 are also shown since this period follows the income tax reforms in 2000 which can be seen to have a modest (upward) impact on the Gini profiles which include that year; see Creedy et al. (2018) for further discussion.

16 Though these ratios are not exactly the equivalent of the Shorrocks (1978) measure, the values are similar to estimates of the Shorrocks R measure reported for Australia, based on 16-year income averages, in Wilkins and Lass (2018). They find $\mathrm{R}=0.836$ (all ages) and $\mathrm{R}=0.813$ (age 18-29 in 2001); see Wilkins and Lass (2018, p. 34). For New Zealand, estimates of Shorrocks's R calculated over 10 years from 2003, yield R=0.896 (all ages) and $\mathrm{R}=0.897$ (age 24-64).
} 
INCOME INEQUALITY IN NEW ZEALAND
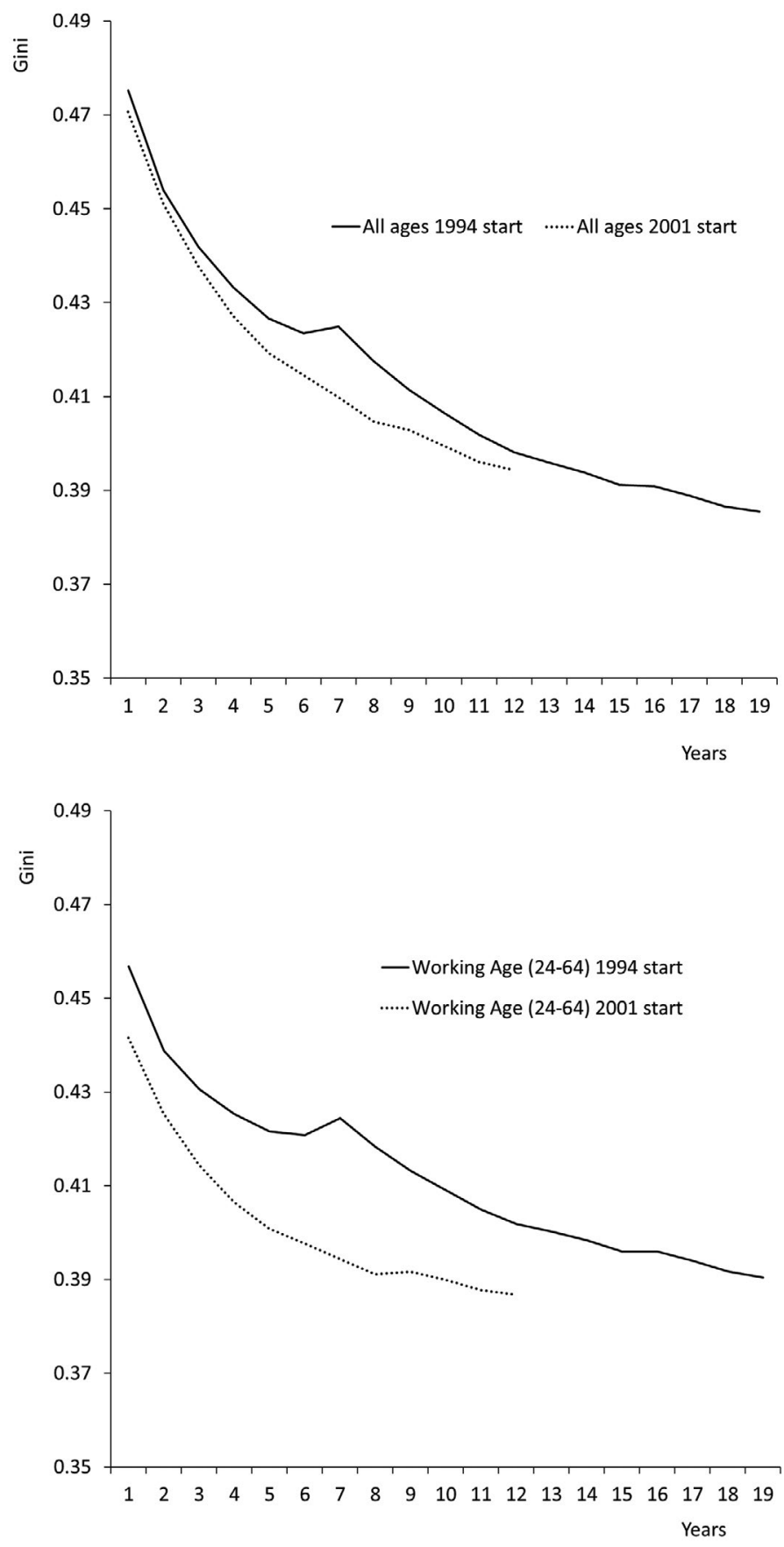

Figure 8. Gini indices for multi-year incomes: New Zealand taxpayers from 1994 and 2001

Source: Authors' calculations using unpublished Inland Revenue confidentialised individual taxpayer data (a 2 per cent random sample made available to the authors). 


\section{Conclusions}

The clear conclusion from this examination is that a great deal of care is required when interpreting evidence on inequality based on income growth rates across deciles (or other divisions) of the income distribution. Since contributors to inequality and poverty debates often begin by asking how increases in incomes or welfare of initially poorer groups compare with those initially better off, the relevant evidence is longitudinal, not cross-sectional.

On the other hand, if concern is with the poorest in any or all periods for which data are being examined, then care needs to be taken to recognise the extent to which people move between income bands over time. In this case, estimating inequality using Gini or similar indices that are measured over several years provides a clearer picture of longer-term inequality as distinct from that which is observed from annual data which include a mixture of persistent and transitory components.

An important caveat to the analysis reported here, as stressed in section 3, is that the comparisons of cross-sectional and longitudinal measures of income inequality are based here on income of individuals. Much of the debate about the level of, or changes in, inequality tends to relate to household inequality, both in New Zealand and Australia. Without access to suitable longitudinal household income data for New Zealand (at least outside of 2002-10), the present analysis has focused on individual taxpayer data. This suggests some caution is warranted with respect to conclusions regarding differences that longitudinal approaches to measuring household inequality and mobility may identify.

However, the evidence here of substantial regression towards the mean across most longitudinal income ventiles, while cross-section-based equivalents display no such tendency, is suggestive that conclusions for household income inequality or mobility could be misleading if based on cross-section data for households. Hopefully, future research will be able to clarify how far these patterns across individual-level incomes are a feature of household-level equivalents.

\section{References}

Azpitarte, F. (2014). Was pro-poor economic growth in Australia for the income-poor? And for the multidimensionally-poor? Social Indicators Research, 117, 871-905. doi.org/ 10.1007/s11205-013-0378-8.

Carter, K. and Gunasekara, F.I. (2012). Dynamics of income and deprivation in New Zealand, 2002-2009. A descriptive analysis of the Survey of Family, Income and Employment (SoFIE) (Public Health Monograph Series No. 24). Wellington: Department of Public Health, University of Otago. 
Creedy, J. (1996). Earnings dynamics over the life cycle: New evidence for New Zealand. New Zealand Economic Papers, 30, 131-153. doi.org/10.1080/00779959609544254.

Creedy, J. (2017). Alternative distributions for inequality comparisons. Australian Economic Review, 50, 484-497. doi.org/10.1111/1467-8462.12238.

Creedy, J., Enright, J., Gemmell, N. and McNabb, N. (2010). Income redistribution and taxes and transfers in New Zealand. Australian Economic Review, 43, 39-51. doi.org/ 10.1111/j.1467-8462.2009.00575.x.

Creedy, J. and Gemmell, N. (2017). Illustrating income mobility: New measures (Working Papers in Public Finance No. 12/2017). Wellington: Victoria Business School, Victoria University of Wellington.

Creedy, J. and Gemmell, N. (2018). Income dynamics, pro-poor mobility and poverty persistence curves. Economic Record, 94(306), 316-328. doi.org/10.1111/1475-4932. 12426.

Creedy, J., Gemmell, N. and Laws, A. (2018). Relative income dynamics of individuals in New Zealand: New regression estimates (Working Papers in Public Finance, No. 06/2018). Wellington: Victoria Business School, Victoria University of Wellington.

Laws, A. (2014). Income mobility and income inequality in New Zealand: Trends, patterns and relationships (Honours dissertation, Victoria University of Wellington, Wellington, New Zealand).

Ministry of Social Development (MSD). (2016, August). Household incomes in New Zealand: Trends in indicators of inequality and hardship 1982 to 2015. Wellington: Ministry of Social Development.

Ministry of Social Development (MSD). (2017, July). Household incomes in New Zealand: Trends in indicators of inequality and hardship 1982 to 2016. Wellington: Ministry of Social Development.

Rashbrooke, M. (ed.). (2013). Inequality. A New Zealand crisis. Wellington: Bridget Williams Books.

Shorrocks, A.F. (1978). Income inequality and income mobility. Journal of Economic Theory, 19, 376-393. doi.org/10.1016/0022-0531(78)90101-1.

Wilkins, R. and Lass, I. (2018). The Household, Income and Labour Dynamics in Australia survey: Selected findings from Waves 1 to 16. The 13th Annual Statistical Report of the HILDA Survey. Melbourne: Melbourne Institute. 


\section{Appendix: New Zealand taxable income distributions 2002 and 2006}

Table A1 provides summary measures of the distribution of taxable income for individuals in 2002 and 2006. These measures are obtained using the 2 per cent samples discussed in section 2.

Table A1. Percentile income levels and ventile average incomes:

New Zealand taxpayers (\$)

\begin{tabular}{|c|c|c|c|c|}
\hline Percentile & $\begin{array}{l}\text { Income at } \\
\text { percentile }\end{array}$ & $\begin{array}{c}\text { Average ventile } \\
\text { income }\end{array}$ & $\begin{array}{l}\text { Income at } \\
\text { percentile }\end{array}$ & $\begin{array}{c}\text { Average ventile } \\
\text { income }\end{array}$ \\
\hline & 2002 & 2002 & 2006 & 2006 \\
\hline 5 & 5,641 & 3,307 & 7,177 & 4,214 \\
\hline 10 & 8,750 & 7,455 & 10,371 & 9,076 \\
\hline 15 & 10,471 & 9,605 & 12,946 & 11,458 \\
\hline 20 & 12,344 & 11,565 & 14,774 & 13,601 \\
\hline 25 & 14,420 & 13,452 & 16,924 & 15,614 \\
\hline 30 & 16,437 & 15,386 & 20,453 & 18,615 \\
\hline 35 & 19,437 & 17,938 & 24,272 & 22,357 \\
\hline 40 & 22,510 & 20,953 & 27,864 & 26,070 \\
\hline 45 & 25,492 & 24,000 & 31,328 & 29,611 \\
\hline 50 & 28,468 & 26,957 & 34,689 & 32,998 \\
\hline 55 & 31,276 & 29,884 & 37,693 & 36,193 \\
\hline 60 & 34,097 & 32,710 & 40,550 & 39,044 \\
\hline 65 & 36,942 & 35,486 & 44,084 & 42,306 \\
\hline 70 & 39,753 & 38,304 & 47,951 & 45,993 \\
\hline 75 & 43,293 & 41,470 & 52,517 & 50,161 \\
\hline 80 & 47,876 & 45,532 & 57,923 & 55,079 \\
\hline 85 & 53,849 & 50,715 & 63,541 & 60,506 \\
\hline 90 & 61,012 & 57,661 & 73,412 & 68,099 \\
\hline 95 & 79,146 & 68,355 & 94,504 & 82,503 \\
\hline $100^{*}$ & 150,033 & 130,329 & 186,437 & 160,030 \\
\hline Overall mean & & 34,038 & & 41,156 \\
\hline
\end{tabular}

Note: * This row shows income at the 99th percentile rather than the top income (100th percentile). However, average ventile income in this row includes all individuals from the 95th to the 100th percentile. Source: Authors' calculations using unpublished Inland Revenue confidentialised individual taxpayer data (a 2 per cent random sample made available to the authors). 
This text is taken from Agenda, Volume 26-Number 1, 2019, edited by William Coleman, published 2019 by ANU Press, The Australian National University, Canberra, Australia.

doi.org/10.22459/AG.26.01.2019.01 